\title{
Small Aircraft RF Interference Path Loss
}

\author{
Truong X. Nguyen, Sandra V. Koppen, Jay. J. Ely, \\ George N. Szatkowski \\ NASA Langley Research Center, Hampton, VA \\ Truong.x.nguyen@nasa.gov
}

\author{
John J. Mielnik, Maria Theresa P. Salud \\ Lockheed Martin Corp., Hampton, VA \\ Hampton, VA
}

\begin{abstract}
Interference to aircraft radio receivers is an increasing concern as more portable electronic devices are allowed onboard. Interference signals are attenuated as they propagate from inside the cabin to aircraft radio antennas mounted on the outside of the aircraft. The attenuation level is referred to as the interference path loss (IPL) value. Significant published IPL data exists for transport and regional category airplanes. This report fills a void by providing data for small business/corporate and general aviation aircraft. In this effort, IPL measurements are performed on ten small aircraft of different designs and manufacturers. Multiple radio systems are addressed. Along with the typical worst-case coupling values, statistical distributions are also reported that could lead to better interference risk assessment.
\end{abstract}

Keywords- interference path loss; portable electronic devices; aircraft; radio; communication; navigation; front-door coupling; PEDs; IPL; IPC;

\section{INTRODUCTION}

Portable electronic devices' (PEDs) interference risk to aircraft radio systems is a concern during flights. For various reasons, many devices such as laptop computers are allowed during flights, while intentional transmitters such as wireless devices and phones are prohibited. On large aircraft, policies are enforced through visual inspections and public announcements before and during critical phases of flights. For small aircraft, policies and enforcement are not as clear. Informal communications with pilots and passengers indicate that the use of wireless devices, including wireless phones, during a flight is likely.

The interference subject is typically studied by addressing the typical source - path loss - victim problem. Addressing the elements include measuring and bounding the emission level of typical devices, the propagation loss, and the interference thresholds for the radio receivers. There have been many past studies addressing the three elements. Examples include emissions measurements from wireless devices in aircraft radio bands [1][2]. Aircraft radio receiver interference thresholds data may be found in [3][4][5].

The propagation loss, also referred to as interference path loss (IPL), is simply the interference signal attenuation between the source location within the passenger cabin (where PEDs are typically located) and the aircraft radio receiver. Low IPL could result in strong interference signals at the receiver, causing an increased likelihood of interference.
A good summary of the publicly available IPL data is documented in [1] and [5]. The dataset includes the lowest IPL data for large aircraft such as a Boeing 747, 757 and 737. On a much more limited scale, IPL data for smaller aircraft were also available. They include data for Canadair Regional Jet, ATR72, and Embraer 120 that can hold 25 seats or more.

For even smaller aircraft, such as those with 20 seats or fewer, there is currently very little publicly available IPL data. Small aircraft may have lower IPL (or higher interference coupling) than large aircraft, since propagation distances between locations within the cabin and the aircraft radio antennas could be significantly shorter. Lower IPL associated with smaller aircraft could translate into higher probability of interference.

This report documents the most recent IPL measurement effort on ten small aircraft. These aircraft models can carry from four to 16 passengers (including flight crew) depending on seat configurations. They differ in aircraft designs, antenna mounting locations, window sizes, diameters, and other parameters that could affect the IPL value. Also included is an aircraft with fiberglass composite skin that provided little shielding, and a helicopter with large glass window areas.

In addition to the traditional minimum IPL values, this paper also reports the data cumulative distribution curves for each system. These distributions may help in assessing the likelihood of interference rather than the typical worst case scenarios.

The data reported here are limited in scope to the "in-band" measurements, or measurements in the radio bands. They are also limited to "front-door" coupling mechanism, in reference to coupling through the aircraft antennas. "Back-door" coupling mechanisms such as coupling via cables and apertures in the enclosure, and out-of-band measurements are considered less of a concern and are excluded.

\section{APPROACH}

As previously discussed, assessment of aircraft radio receiver interference is typically accomplished by addressing the source - path loss - victim components of the equation:

$$
A+B \geq C \text {, }
$$

for all in-band frequencies, where

" $A$ " is the maximum RF emission from a PED in $\mathrm{dBm}$, 
" $B$ " is the maximum aircraft interference path coupling value in $\mathrm{dB}$, and is a negative value. " $-\mathrm{B}$ ” is referred to as the minimum IPL and is positive,

" $C$ " is the receiver's minimum in-band, on-channel interference threshold in $\mathrm{dBm}$.

If the minimum interference threshold, "C", is lower than the maximum interference signal level at the receiver's antenna port, " $(A+B)$ ", there is a potential for interference. This is typical of the "worst case" analysis, in which the worst cases of all components are assumed. "Worst case" analysis can be overly conservative if the worst-case data are far from the norm.

In order to avoid overly conservative analysis, one approach was to perform the analysis using some statistical parameters other than the worst-case. Thus, the chosen statistical parameters of " $\mathrm{A}$ " are added to similar statistical parameters of " $\mathrm{B}$ ", and the results are compared against some other statistical forms of " $C$ ". The desired statistics parameters are not yet agreed upon by the involved technical community. In this paper, the primary focus is to provide small aircraft interference path coupling value, "B". A secondary focus is to report the statistical distribution of the measured IPL data, from which acceptable parameters may be determined.

\section{A. Aircraft and Systems Considered}

Table I listed the ten aircraft on which the IPL measurements were performed. The aircraft include smaller models that can carry four to 16 passengers. All aircraft have metal skins with the exception of the Cirrus model with all composite skin. Experiments show that the composite skin provides little RF shielding between the internal cabin and radio antennas mounted on the top of the aircraft. Also included was a Bell 407 helicopter with large glass surfaces all around the cabin. Fig. 1 and Fig. 2 show the smallest and the largest aircraft measured. For this paper, each model was also assigned an integer number that could be useful in the organization of data and plots. The numbers were associated with the measurement order.

TABLE I. AIRCRAFT MEASURED

\begin{tabular}{|l|l|l|}
\hline \multicolumn{1}{|c|}{$\begin{array}{c}\text { Aircraft } \\
\text { Designation }\end{array}$} & \multicolumn{1}{|c|}{ Aircraft Model } & \multicolumn{1}{c|}{ Types } \\
\hline 1- Cirrus & Cirrus SR-22 GTS & Four-seat light composite \\
\hline 2- Cessna 172 & Cessna 172R Skyhawk & Four-seat light \\
\hline 3- Bell 407 & Bell 407 & Seven-place utility helicopter \\
\hline 4- LearJet & $\begin{array}{l}\text { Bombardier LearJet } \\
\text { 35A }\end{array}$ & $\begin{array}{l}\text { Ten-seat Light/midsize } \\
\text { corporate jet }\end{array}$ \\
\hline 5- Sabreliner & Rockwell Sabreliner 65 & $\begin{array}{l}\text { Ten to 12-seat medium } \\
\text { corporate jet }\end{array}$ \\
\hline 6-Citation II & $\begin{array}{l}\text { Cessna Citation II } \\
\text { (model 550) }\end{array}$ & $\begin{array}{l}\text { Eight to 12-seat light corporate } \\
\text { jet }\end{array}$ \\
\hline 7- Baron 58 & $\begin{array}{l}\text { Raytheon Beechcraft } \\
\text { Baron B-58 }\end{array}$ & Four- to six-seat business \\
\hline 8- Piper Saratoga & $\begin{array}{l}\text { Piper PA-32R-301 } \\
\text { Saratoga II HP }\end{array}$ & Six-seat light \\
\hline 9- Gulfstream GII & Gulfstream GII & $\begin{array}{l}\text { Ten to 16-seat large corporate } \\
\text { jet }\end{array}$ \\
\hline 10-King Air & Raytheon King Air 200 & $\begin{array}{l}\text { Eight to 12-seat medium } \\
\text { corporate turboprop }\end{array}$ \\
\hline
\end{tabular}

TABLE II. AIRCRAFT RADIO SYSTEMS CONSIDERED

\begin{tabular}{|c|c|c|}
\hline Aircraft Band & $\begin{array}{c}\text { Receive } \\
\text { Spectrum (MHz) }\end{array}$ & $\begin{array}{c}\text { Measurement } \\
\text { Frequency Range } \\
\text { (MHz) }\end{array}$ \\
\hline LOC & $108.1-111.95$ & $108-118$ \\
\hline VOR & $108-117.95$ & $118-138$ \\
\hline VHF-Com & $118-138$ & $325-340$ \\
\hline GS & $328.6-335.4$ & $960-1220$ \\
\hline DME & $962-1213$ & $1020-1040$ \\
\hline ATC & 1030 & $1080-1100$ \\
\hline TCAS/TCAD & 1090 & $1565-1585$ \\
\hline GPS (L1) & $1575 \pm 2$ & \\
\hline
\end{tabular}

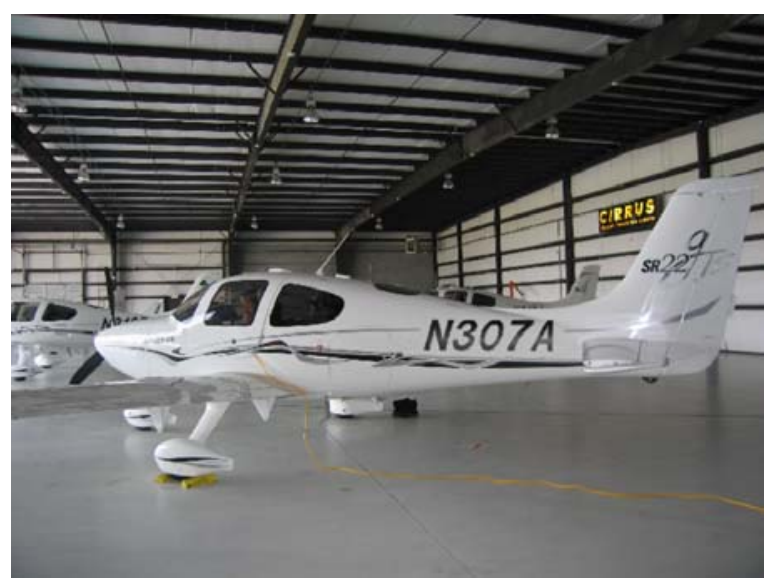

Figure 1. Cirrus SR22 GTS, the smallest aircraft measured

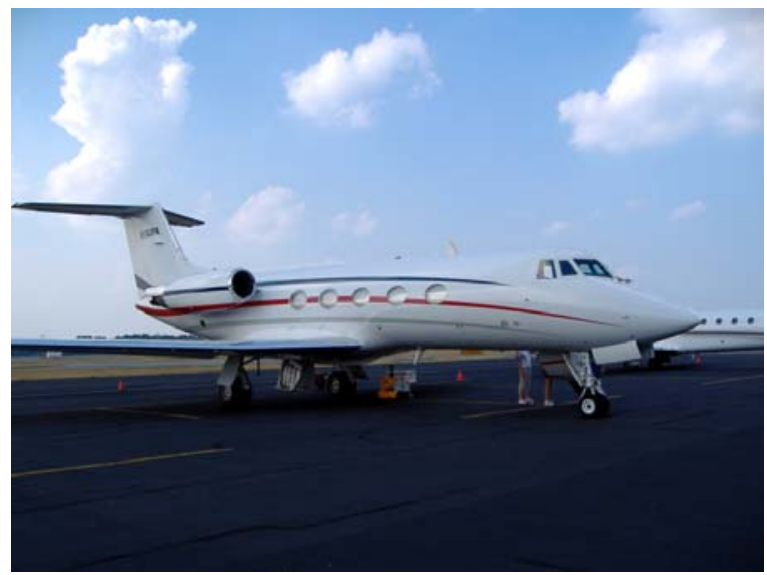

Figure 2. Gulfstream GII, the largest aircraft measured.

This effort attempts to address all of the radio systems listed in Table II to the maximum extent possible. The systems considered include Localizer (LOC), Very High Frequency Omnidirectional Range (VOR), Very High Frequency Voice Communication (VHF-Com), Glideslope (GS), Air Traffic Control Radar Beacon System (ATC), Distance Measuring Equipment (DME), Air Traffic Control Radar Beacon System (ATC), Traffic Collision Avoidance System (TCAS) or Traffic Collision Alert Device (TCAD), and Global Positioning System (GPS).

The available radio systems and their antennas varied widely among the aircraft used. They varied in receiver and antenna designs, manufacturers, and mounting locations. 
There were often secondary systems that were different from the primary system, and often the two systems may not share the external antennas. Measurement of secondary system may have been performed if there were significant differences in the aircraft antenna locations and paths. However, due to system availability, aircraft size, and time limitations, a complete data set for all secondary systems was not obtained.

\section{B. Measurement Method}

Fig. 3 illustrates the representative interference coupling paths between the aircraft windows and door, and a topmounted antenna. For metal aircraft, windows and door seams typically provide the strongest coupling paths to the external antennas [6].

Fig. 4 illustrates a typical setup that was very similar to that used in the past studies [1]. A small antenna, driven by a tracking generator, is used to simulate a transmitting source in the cabin. While performing synchronized sweeps with the tracking generator, a spectrum analyzer captures the envelope of the simulated signal that coupled into aircraft antennas.

The IPL value is the attenuation, in $\mathrm{dB}$, between transmitted power at point (1) and the measured power at point (2). For GPS, IPL is defined to be the difference in power between locations (1) and (3). Or,

$$
\begin{aligned}
I P L & =P^{T}(1)-P^{R}(2) \quad \text { for most systems, and } \\
& =P^{T}(1)-P^{R}(3) \quad \text { for GPS, }
\end{aligned}
$$

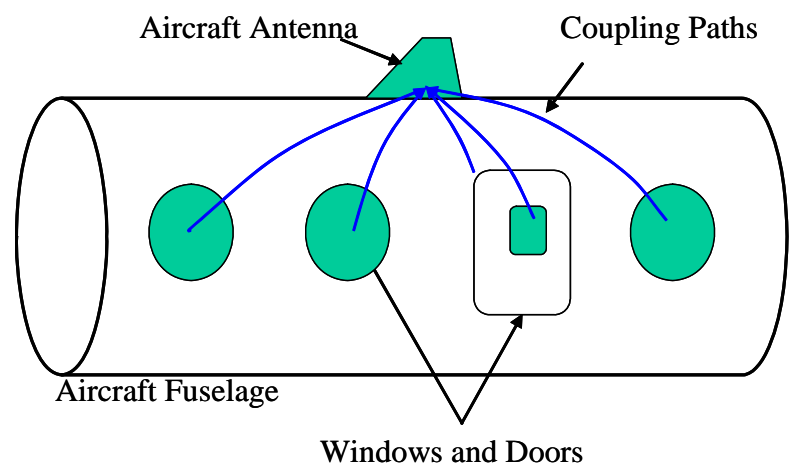

Figure 3. Representative interference coupling paths.

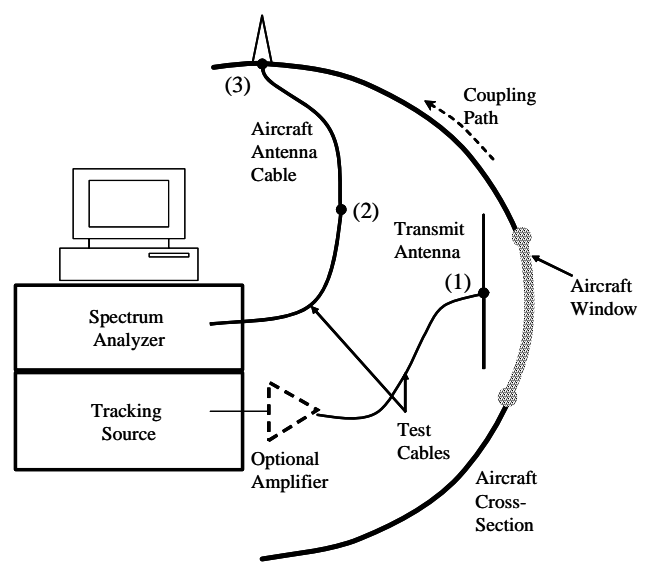

Figure 4. Typical measurement setup. where $P^{T}(1)$ is power transmitted at point (1); $P^{R}(2)$ and $P^{R}(3)$ are power received at points (2) and (3), in $\mathrm{dBm}$, respectively.

Measurement at point (2) is performed at the receiver, while measurement at point (3) is performed at the output of the aircraft antenna. These points correspond to the specific locations at which individual receiver interference threshold is defined [5]. The interference path coupling (IPC) value is simply the negative of the IPL value, or $I P C=-I P L$.

In most measurements reported here, lack of access to the rear of the GPS antenna made it difficult to measure at point (3) directly. As a result, measurements at point (2) were performed, and Eq. (2) was applied instead. This deviation resulted in additional uncertainties due to the unknown aircraft GPS antenna cable loss that was not accounted for in the analysis. Since GPS antennas are typically mounted close to their receivers, the cable loss is expected to be small, possibly less than $2 \mathrm{~dB}$.

\section{1) Transmit Antenna Volumetric Scan}

The volume of each aircraft was divided into small cells for volumetric scanning. While the tracking generator and the spectrum analyzer performed synchronized sweeps, test personnel moved the transmit antenna physically throughout volume of each cell, and the maximum envelope trace was recorded. Each cell typically included scans for vertical and horizontal polarizations. Once complete, the entire volume of the passenger cabin, the cockpit, and in many cases the cargo bay, were covered.

\section{2) Transmit Antennas}

The transmit antennas used for IPL measurements typically include half-wave dipoles. Due to bandwidth limitations and size associated with dipole antennas, a bi-conical antenna was used for frequencies below $350 \mathrm{MHz}$, and a dual-ridge horn antenna above $960 \mathrm{MHz}$. The bi-conical antenna was in-band (low mismatch and efficient) from $300 \mathrm{MHz}$ to $1 \mathrm{GHz}$, but was usable down to $100 \mathrm{MHz}$. The bi-conical antenna is isotropic in one plane, where as the dual-ridge horn antenna is directional. The data were then corrected for the transmit antenna gain (relative to a dipole) to conform to the practice recommended in [5]. Section II.D discusses this correction in greater details.

\section{3) Indoor Measurements}

It is noted that most measurements were performed with the aircraft located inside a large hangar. Extreme weather conditions could pose potential health hazards if the measurements were performed outside. While this setup was not ideal, limited experimentation confirmed that data were not significantly affected if aircraft antennas were kept far away from building structures.

There are benefits to performing measurements inside a hangar, however. The hangar helped shield the aircraft from strong local transmitters operating in the measurement bands. As a result, fewer data points were tainted by the ambient signals that would have to be manually removed from the data set. The Gulfstream GII was the only aircraft measured outside the hangar. 


\section{Instrument and Settings}

An Agilent E4407B spectrum analyzer with an internal tracking source was used for all measurements. In each measurement band, 401-point frequency sweeps were performed while the instrument was set at trace maximum hold. All instrument settings were pre-determined and stored in the spectrum analyzer's memory to allow quick recalls during the measurement. This approach allowed for fast switching between measurement bands and reduced operator errors. At the end of position sweeps (when the data envelope had converged), the trace was downloaded to a computer for later processing.

The instrument settings were selected for maximum measurement speed and sensitivity. Laboratory verifications were also performed to ensure slow sweep rate sufficient to accommodate long cable length and propagation delays.

\section{Data Calibration and Corrrections}

In addition to the raw IPL data, cable loss, system noise floor, and ambient noise environment reaching the measurement systems were also measured. Microsoft Excel was used for post calibration and processing. Data were processed according to the Eq. 2 and Eq. 3. Statistical calculations were performed using Matlab.

Other correction factors were also applied. As previously discussed, one accounted for the use of a different transmit antenna than a dipole. Using the process in [5], the data were corrected for the transmit antenna gain relative to a dipole. This correction approximated the setup as if a dipole transmit antenna was used instead. The correction factors are outlined in Table III. While this correction is not ideal, i.e. using a farfield gain rather than near-field gain, it is a reasonable effort to standardize the results performed under different efforts, while allowing use of other antennas to overcome deficiencies of dipole antennas.

The other correction was to remove the effects of the GPS antennas' built-in pre-amplifiers. This correction was needed since the GPS receiver interference threshold was specified for a passive GPS antenna [7]. The aircraft GPS antennas' built-in pre-amplifier had either $26.5 \mathrm{~dB}$ or $15.7 \mathrm{~dB}$ gain, depending on models. These nominal values were from the devices' technical specifications, or supplied by the manufacturers for this analysis.

Fig. 5 shows example results of the aircraft measurement. Each trace represents the calibrated and processed IPC data from the volumetric scanning of each cell, where each cell represents a small volume space in the cabin. Due to the high number of traces, the individual traces are not identified here. Also shown are the measurement noise floor and ambient trace that were calibrated and processed as if it was real data. This trace verifies that sufficient measurement dynamic range was used, and helps to identify data points that were affected by strong ambient signals. Ambient signals were typically represented by strong but narrowband spikes. Any corrupted data points were individually identified and removed from the traces before plotting and conducting statistical calculations. The systems most affected by strong ambient signals typically include LOC, GS, DME, VHF-Com bands.
TABLE III. TRANSMIT ANTENNA FAR-FIELD GAIN CORRECTION FACTOR

\begin{tabular}{|c|c|c|c|}
\hline $\begin{array}{c}\text { Radio Systems } \\
\text { Considered }\end{array}$ & $\begin{array}{c}\text { Meas. Freq } \\
\text { Range } \\
\text { (MHz) }\end{array}$ & Transmit Antenna & $\begin{array}{c}\text { Far-field Gain } \\
\text { Correction } \\
\text { Factor (dBd) }\end{array}$ \\
\hline VORLOC & $108-118$ & Bi-conical & +12.85 \\
\hline VHF-Com & $118-138$ & Bi-conical & +10.9 \\
\hline GS & $325-340$ & Bi-conical & -1.03 \\
\hline DME & $960-1220$ & Dual-Ridge Horn & -5.32 \\
\hline ATCRBS & $1020-1040$ & Dual-Ridge Horn & -4.85 \\
\hline TCAS/TCAD & $1080-1100$ & Dual-Ridge Horn & -5.26 \\
\hline GPS & $1565-1585$ & Dual-Ridge Horn & -7.5 \\
\hline
\end{tabular}

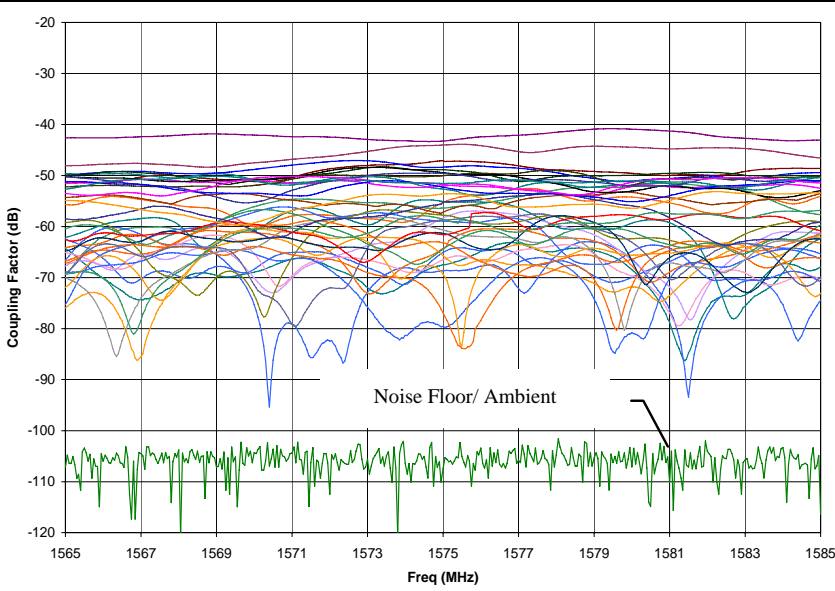

Figure 5. Cirrus SR22-GTS individual GPS interference path coupling measurement scans (example).

\section{E. Statistical Analysis}

In performing statistical analysis on the data, measurement location and source frequency were both considered. With the exception of the noise floor trace, all data traces were considered to account for all spatial positions. In addition, all data points in each trace were also used to account for the variations with respect to frequency. The total number of points used was roughly equal to the number of traces times the 401 frequencies per trace.

The mean value of the data set is computed using the data in linear units before converting back to the $\mathrm{dB}$ value. Table IV shows an example of the basic statistics of one data set.

TABLE IV. GPS INTERFERENCE PATH COUPLING FACTOR STATISTICS FOR CIRRUS SR22 GTS (IN DB) - EXAMPLE

\begin{tabular}{|c|c|cc|}
\hline Maximum & -40.8 & No. of Points: & 15238 \\
98 percentile & -42.7 & & \\
95 percentile & -47.4 & No. of Position & 38 \\
90 percentile & -49.6 & Scans: & \\
80 percentile & -51.0 & No. of Freqs/ Sweep & 401 \\
50 percentile & -58.4 & & \\
Mean & -52.6 & &
\end{tabular}

\section{RESULTS}

For the remaining figures, IPC data are reported for the ten aircraft. IPC and IPL are loosely interchangeable as they refer to the same data, but with the IPC values being the negative of the IPL values. The IPL term is more widely recognized, while plots of IPC data are often more intuitive. 
Tables V and VI summarize all the measurements by reporting the peak IPC values. These data are in the similar forms as reported in [1][3][5] (except negative). Measurements on secondary systems are labeled, if performed, such as DME2 and GPS2. The remaining data were measured on either the only system available, or the primary system.

Fig. 6 to Fig. 11 expand the data further by reporting the cumulative distribution of the IPC data for each aircraft system. The peak IPC value for each curve is the same as reported in the Tables V and VI.

As can be seen from the data, IPC data vary widely between aircraft models. The peak values may vary by as much as $25 \mathrm{~dB}$ or greater in some cases. The cumulative distribution curves, on the other hand, often appear to be similar in shapes in a general sense. Further analysis may be needed to explain and utilize this attribute for characterizing aircraft IPC (or IPL). Additional details concerning results and statistical parameters can be found in [8].

Similar frequency data has been obtained during past measurements on larger aircraft, but has not been evaluated in this manner. Such data presentation and analysis would improve PED interference risk assessment

TABLE V. PEAK INTERFERENCE PATH COUPLING VALUES FOR VOR, LOC, VHF-COM AND GS (IN DB)

\begin{tabular}{|c|c|c|c|c|}
\hline \multirow[b]{2}{*}{ Aircraft } & \multirow{2}{*}{$\begin{array}{l}\text { VOR- } \\
\text { LOC }\end{array}$} & \multicolumn{2}{|c|}{ VHF-Com } & \multirow[b]{2}{*}{ GS } \\
\hline & & $\begin{array}{l}\text { VHF- } \\
\text { Com1 } \\
\end{array}$ & $\begin{array}{l}\text { VHF- } \\
\text { Com2 } \\
\end{array}$ & \\
\hline Cirrus & -22.0 & -8.7 & -27.1 & -41.4 \\
\hline Cessna 172R & -26.9 & -14.3 & & -36.3 \\
\hline Bell 407 & -17.6 & -21.2 & & \\
\hline LearJet & -29.8 & & -35.5 & -38.3 \\
\hline Sabreliner & -38.1 & & & -46.7 \\
\hline Citation II & -36.1 & -35.1 & -26.9 & -41.0 \\
\hline Baron 58 & & -16.6 & -28.6 & -43.7 \\
\hline Piper Saratoga & -27.9 & -15.9 & -17.0 & -46.3 \\
\hline Gulfstream GII & -42.7 & -22.2 & -35.1 & -52.1 \\
\hline King Air & -41.1 & -35.6 & -30.2 & -40.2 \\
\hline
\end{tabular}

TABLE VI. Peak InTERFERENCE Path Coupling VAlues for ATC, DME, TCAS/TCAD AND GPS (IN DB)

\begin{tabular}{|l|c|c|c|c|}
\hline \multicolumn{1}{|c|}{ Aircraft } & ATC & DME & $\begin{array}{c}\text { TCAS/ } \\
\text { TCAD }\end{array}$ & GPS \\
\hline Cirrus & -43.5 & & -33.4 & $-40.8^{(\mathrm{d})}$ \\
\hline Cessna 172R & -45.1 & & & -50.8 \\
\hline Bell 407 & -43.3 & & & -48.3 \\
\hline LearJet & -52.4 & -54.0 & & -54.9 \\
\hline Sabreliner & & & & -58.4 \\
\hline Citation II & -55.2 & -48.5 & -52.8 & $-51.6^{(\mathrm{c})}$ \\
\hline Baron 58 & -50.1 & & -41.0 & $-49.0^{(\mathrm{d})}$ \\
\hline Piper Saratoga & -51.6 & -51.6 & & -38.6 \\
\hline Gulfstream GII & -63.5 & -61.1 & -58.4 & -65.2 \\
\hline King Air & -52.2 & $-49.4^{(\mathrm{a})}$ & -33.4 & -55.3 \\
\hline
\end{tabular}

(a) DME1; (b) DME2; (c) GPS1; (d) GPS2

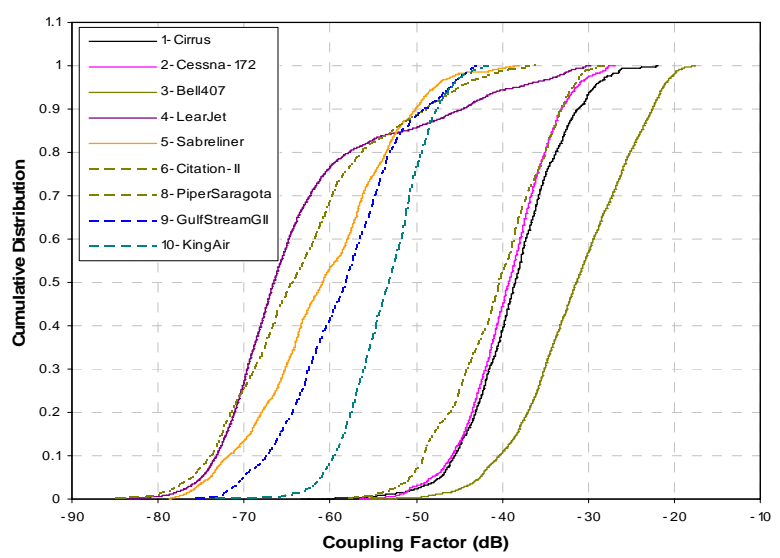

Figure 6. VOR and LOC interference path coupling cumulative distributions.

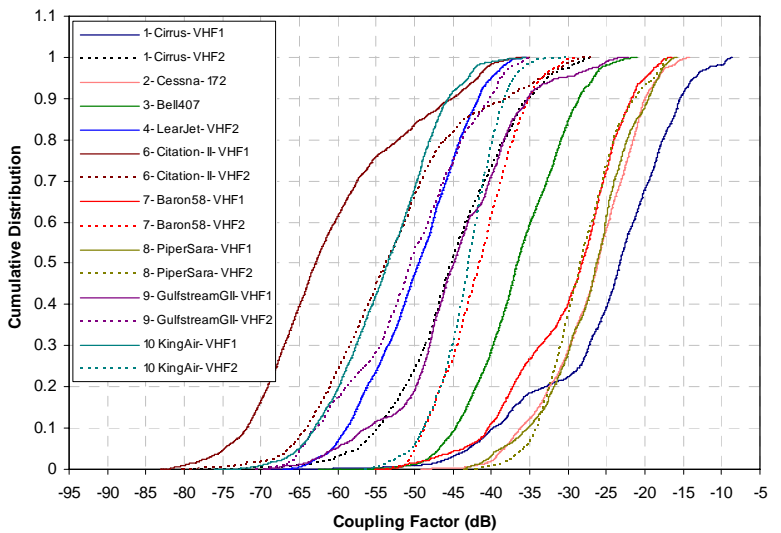

Figure 7. VHF-Com interference path coupling cumulative distributions.

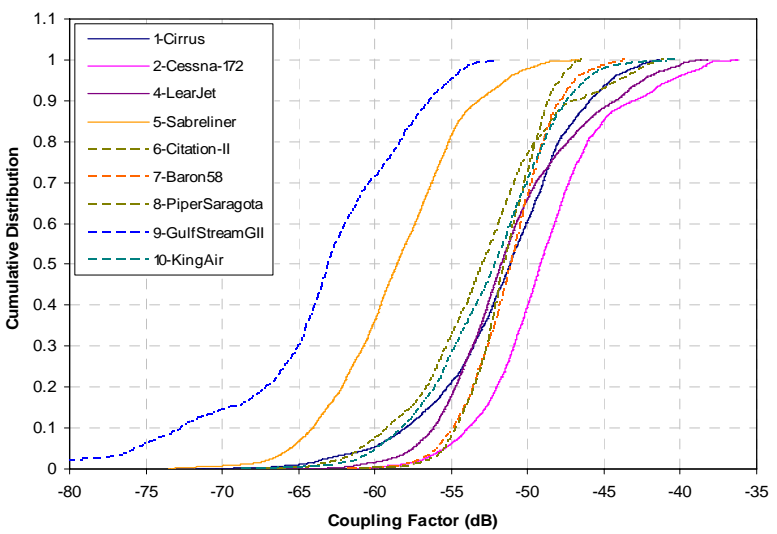

Figure 8. GS interference path coupling cumulative distributions. 


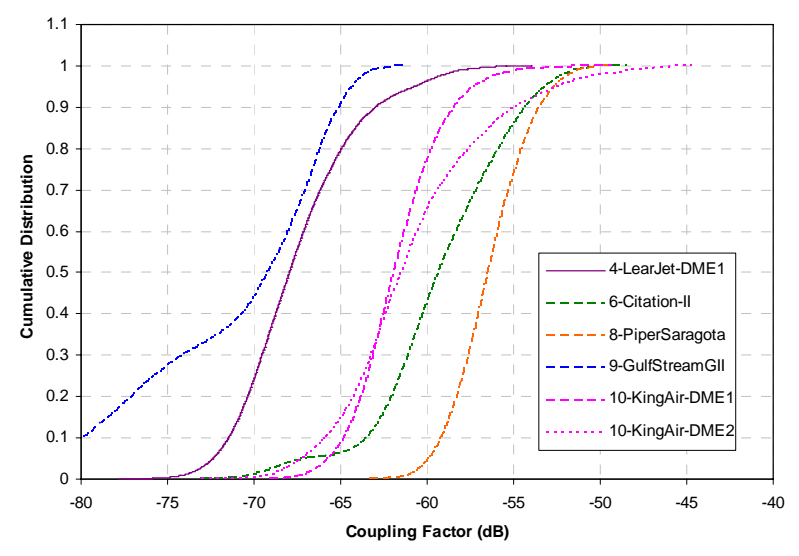

Figure 9. DME interference path coupling cumulative distribution.

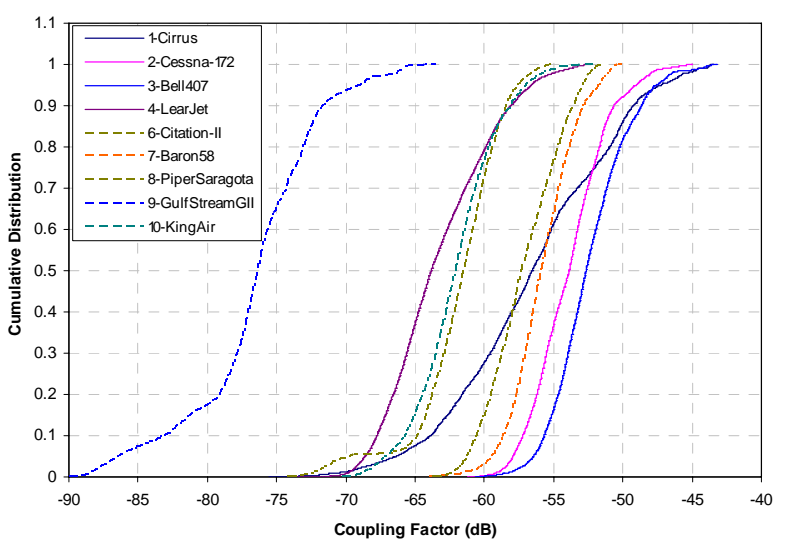

Figure 10. ATC interference path coupling cumulative distribution.

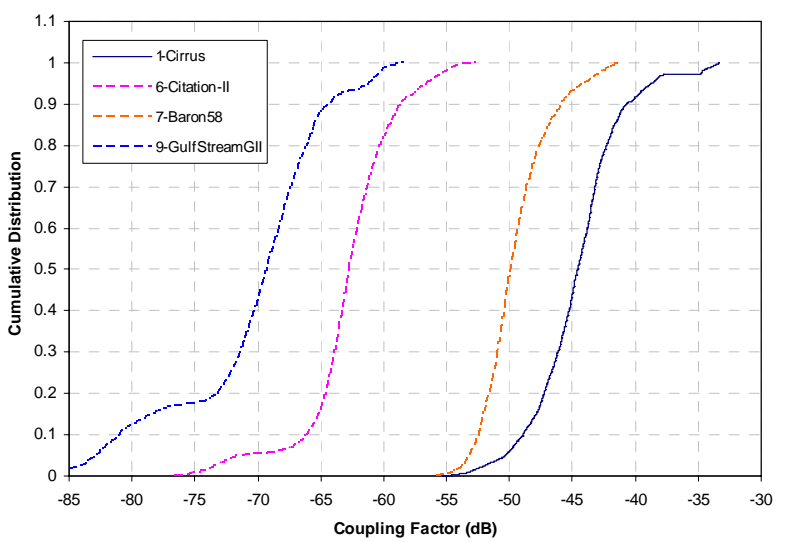

Figure 11. TCAS/TCAD interference path coupling cumulative distribution.

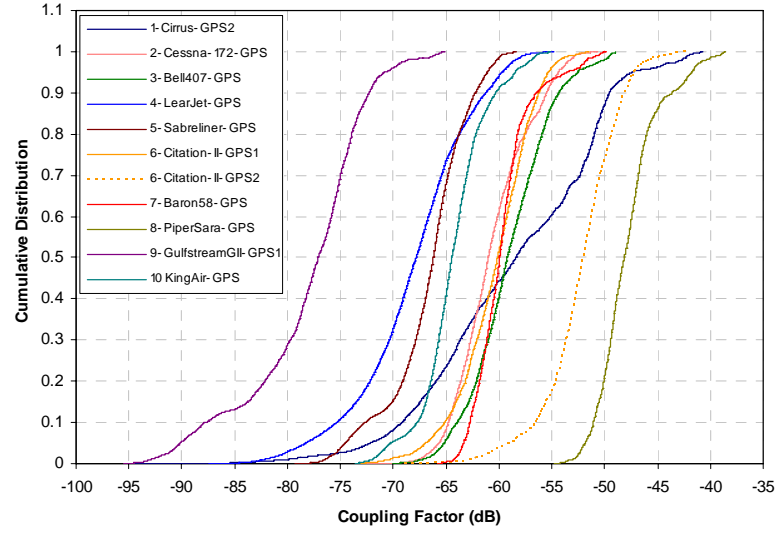

Figure 12. GPS interference path coupling cumulative distribution.

\section{SUMMARY AND CONCLUSIONS}

Interference coupling factor (or interference path loss) data were measured for multiple radio systems on ten small aircraft. The data show significant data variations between different aircraft models. Data cumulative distribution curves show similar shapes even for different aircraft models. Further analysis may be needed to validate and utilize this characteristic.

\section{ACKNOWLEDGEMENTS}

This work was supported by the FAA Aviation Safety Organization and the NASA Aviation Safety Program.

\section{REFERENCES}

[1] T. X. Nguyen, S. V. Koppen, J. J. Ely, R. A. Williams; L. J. Smith, and M. T. Salud, "Portable Wireless LAN Device and Two-Way Radio Threat Assessment for Aircraft Navigation Radios", NASA/TP-2003212438, July 2003.

[2] T. X. Nguyen, S. V. Koppen, L. J. Smith, R. A. Williams and M. T. P. Salud, "Thrid Generation Wireless Phone Threat Assessment for Aircraft Communication and Navigation Radios", NASA/TP-2005213537, March 2005.

[3] RTCA/DO-199, "Potential Interference to Aircraft Electronic Equipment from Devices Carried Aboard”, September 16, 1988.

[4] RTCA/DO-233, "Portable Electronic Devices Carried On Board Aircraft”, Prepared by SC-177, August 20, 1996.

[5] RTCA/DO-294, "Guidance on Allowing Transmitting Portable Electronic Devices (T-PEDs) on Aircraft”, October 19, 2004.

[6] M. Jafri, J. Ely, and L. Vahala, "Graphhical and Statistical Analysis of Airplane Passenger Cabin RF Coupling Paths to Avionics” $22^{\text {nd }}$ Digital Avionics Systems Conference, October 12-16, 2003

[7] RTCA/DO-235A, "Assessment of Radio Frequency Interference Relevant to the GNSS”, December 5, 2002. Table 2-2 footnote.

[8] T. X. Nguyen, S. V. Koppen, J. J. Ely, G. N. Szatkowski, J. J. Mielnik, and M. T. Salud, "Small Aircraft Radio Frequency Interference Path Loss", NASA/TP, to be published. 